\title{
PENGGUNAAN PISAU SADAP Bi-Cut UNTUK MENUNJANG EFEKTIVITAS DAN EFISIENSI PADA PERKEBUNAN KARET
}

\author{
Utilizing of Bi-Cut as Tapping Knife for Effectivity and Efficiency on Rubber Plantation \\ Irwan Suhendry, Andi Wijaya, dan Sayurandi \\ Balai Penelitian Sungei Putih, Pusat Penelitian Karet, PO Box 1415 Medan 20001 \\ Email : andi.puslitkaret@gmail.com
}

Diterima 19 Juli 2018 / Direvisi 16 Oktober 2018 / Disetujui 15 November 2018

\begin{abstract}
Abstrak
Lateks tanaman karet dipanen melalui proses penyadapan. Penyadapan dilakukan dengan cara mengiris kulit menggunakan pisau sadap dengan sistem tertentu. Produksi tanaman karet selain ditentukan oleh potensi genetik masing-masing klon juga sangat ditentukan oleh sistem eksploitasi. Dalam sistem eksploitasi, kualitas penyadapan berkaitan dengan luka kayu maupun konsumsi kulit yang memperpanjang umur ekonomis sehingga produksi karet dalam satu siklus dapat lebih tinggi. Konsumsi kulit yang terkendali mempengaruhi umur ekonomis karet menjadi lebih lama sehingga produksi karet satu siklus dapat lebih tinggi. Pada 10 tahun terakhir perusahaan perkebunan mengalami kesulitan mendapatkan penyadap terampil. Upaya mengatasi hal tersebut sangat diperlukan rancangan pisau sadap yang mampu mengendalikan konsumsi kulit dan luka kayu. Tim peneliti Balai Penelitian Sungei Putih sejak tahun 2016 telah berhasil merancang pisau sadap ergonomis yang diberi nama pisau sadap Bi-cut untuk penyadapan panel sadap bawah (BO). Berdasarkan hasil pengujian pisau tersebut dapat dilihat bahwa kecepatan penggunaan prototipe pisau sadap Bi-cut lebih lambat dibandingkan penggunaan pisau sadap konvensional yaitu sebesar 4.69 detik per pohon. Konsumsi kulit menggunakan pisau sadap konvensional lebih tebal yaitu sebesar 2,73 $\mathrm{mm}$ dibandingkan dengan pisau sadap ergonomis yaitu sebesar $1,40 \mathrm{~mm}$, namun tidak berbeda nyata terhadap produksi lateks. Keunggulan pisau sadap Bi-
\end{abstract}

cut ini adalah dapat mencegah pelukaan kayu dan tebal irisan sadapan lebih tipis. Bi-cut mampu menyadap satu panel sadap BO selama 7,74 tahun/panel sadapan atau sekitar 30,96 tahun selama siklus produksi.

Kata kunci: Hevea brasiliensis, konsumsi kulit, luka kayu, pisau Bi-cut.

Abstract
Natural rubber latex could be obtained by
tapping rubber tree. The tapping is done by incision
of the bark using a tapping knife with a particular
system. Production of rubber plant is not only
determined by the genetic of clone, but also
determined by system of exploitation. In system of
exploitation, the quality of tapping related to wood
wound and consumption of bark and which
lengthen the economic life span of rubber, hence the
rubber production in one cycle can be higher. In the
last over 10 years, the plantation companies had
difficulty in getting skilled tappers. The new type of
tapping knife which can control ability for the
consumption of tree's bark and wood wound was
neccesary developed. The research team of Sungei
Putih Research Center in 2016 had succeeded in
designing an ergonomic tapping knife, namely Bi-
cut tapping knife which usefully for downward
tapping (BO). The result showed that the tapping by
using Bi-cut was slower than the conventional
tapping knife, about 4.69 second per tree, however
the bark consumption using conventional tapping
knife was thicker about 2.73 mm than using Bi-cut
tapping knife about 1.40 mm. The difference of bark
consumtion didn't significantly affect on latex yield.
The advantage of Bi-cut is that it can control wood


wounds and consumption of bark. Bi-cut was able to tap BO for 7.74 years/ tapping panel or about 30.96 years during the production cycle.

Key words: Hevea brasiliensis, bark consumption, wood wound, ergonomic tapping knife.

\section{Pendahuluan}

Pencapaian produktivitas karet yang tinggi dan jangka panjang merupakan tujuan utama dalam agribisnis karet. Selain penggunaan bahan tanam yang berkualitas, kultur teknis yang baik, dan pemeliharaan tanaman secara optimal, produksi yang tinggi dapat dicapai melalui penggunaan sistem eksploitasi dan manajemen penyadapan yang sesuai dengan karakteristik klon (Sumarmadji et al., 2009; Sumarmadji et al., 2003; Sumarmadji et al., $2003^{b}$ ). Klon-klon unggul baru mampu mencapai produktivitas sebesar 35 - 40 ton selama satu siklus (20 - 25 tahun) dengan mengikuti norma penyadapan yang benar (Siagian \& Siregar, 2013; Woelan et al., 2012). Pencapaian potensi produksi tersebut sangat dipengaruhi oleh kualitas penyadapan. Kualitas penyadapan akan menentukan lama atau singkatnya masa penyadapan tanaman karet. Di sisi lain, kualitas hasil penyadapan yang prima hanya dapat dicapai oleh tenaga penyadap yang terampil, terlatih dan berpengalaman.

Seiring dengan perkembangan zaman, perusahaan perkebunan karet umumnya mengalami kesulitan dalam mendapatkan tenaga penyadap dengan keterampilan tinggi dan mampu menghasilkan mutu sadap sesuai mutu standar (Harieswantini et al., 2017). Kelangkaan tenaga tersebut dipengaruhi oleh tersedianya lapangan kerja alternatif dari sektor industri lain (Pane et al., 2017). Kelangkaan penyadap juga memicu perusahaan perkebunan karet untuk melakukan sistem sadap frekuensi rendah dan menggunakan sistem sadap alternatif untuk menekan biaya penyadapan (Nugrahani et al., 2017; Setiono et al., 2016; Soumahin et al., 2010; Siregar et al., 1997). Di samping itu, ratarata pendidikan angkatan kerja muda yang semakin tinggi menyebabkan mereka tidak tertarik bekerja di area yang bersifat dirty work seperti penyadap. Keadaan tersebut diperparah dengan pelatihan-pelatihan keterampilan penyadap yang minim dan beban kerja yang meningkat.

Salah satu faktor yang mempengaruhi produktivitas tanaman karet adalah sistem sadap dan kualitas penyadapan (Sumarmadji et al., 2009; Siregar et al., 1997). Hendaryati \& Arianto (2017) (Tabel 1) melaporkan bahwa capaian produktivitas tanaman karet secara umum dalam kurun lima tahun terakhir masih tergolong rendah, yaitu hanya sebesar 1.060 $\mathrm{kg} / \mathrm{ha}$, artinya produktivitas tanaman karet masih dapat ditingkatkan dengan pola konsumsi kulit yang hemat selain penggunaan klon unggul (Junaidi \& Kuswanhadi, 1998). Buruknya kualitas penyadapan dapat ditandai oleh konsumsi kulit yang boros karena sayatan kulit yang terlalu tebal, luka kayu karena menyadap terlalu dalam atau sudut sadap yang semakin datar sehingga alur sadap semakin pendek. Hal tersebut dilakukan sebagai upaya untuk memenuhi tuntutan target produksi

Tabel 1. Produktivitas tanaman karet di Indonesia

\begin{tabular}{cc}
\hline Tahun & Produktivitas tanaman karet $(\mathrm{kg} / \mathrm{ha})$ \\
\hline 2011 & 1.071 \\
2012 & 1.073 \\
2013 & 1.083 \\
2014 & 1.053 \\
2015 & 1.036 \\
2016 & 1.045 \\
Rataan & 1.060 \\
\hline
\end{tabular}

Sumber : Hendaryati \& Arianto (2017) diolah 
yang tinggi sehingga menyebabkan kualitas sadapan rendah yang dapat menimbulkan kering alur sadap (Andriyanto \& Tistama, 2014; Jacob \& Krishnakumar, 2006; Senevirathna et al., 2007; Jacob et al., 1989). Sebagai akibat kurang terampilnya tenaga penyadap menyebabkan jumlah populasi tanaman kurang produktif yang berpengaruh kepada capaian produktivitas tanaman karet di bawah standar, yaitu hanya sebesar 13-26 ton/ha. siklus (Siagian \& Siregar, 2011). Wibowo (2017) melaporkan bahwa rata-rata konsumsi kulit sadapan dengan menggunakan pisau sadap manual hanya mampu mencapai $2,15 \mathrm{~mm} /$ sadapan, padahal penggunaan kulit sadapan yang dianjurkan adalah tidak melebihi $1,50 \mathrm{~mm} / \mathrm{sadapan}$. Pemborosan pemakaian kulit menyebabkan umur ekonomis tanaman dapat tercapai. Fenomena tersebut merupakan fakta umum di perkebunan karet yaitu kulit bidang sadap yang cepat habis dan munculnya benjolan-benjolan akibat luka kayu pada batang. Benjolanbejolan tersebut berpengaruh pada kualitas kulit pulihan (Gambar 1), sehingga kulit pulihan tidak dapat diharapkan lagi.

Langkah untuk mengantisipasi kelangkaan tenaga penyadap terampil perlu dilakukan agar mutu sadap yang tetap prima selama umur ekonomis tanaman karet dan potensi produksi klon dapat dicapai. Inovasi teknologi penyadapan diperlukan untuk mengurangi ketergantungan terhadap tenaga penyadap yang terampil. Teknologi sekaligus dapat mengontrol mutu sadap pada saat penyadap mengiris pohon karet perlu dikembangkan berupa inovasi pisau sadap ergonomis yang dilengkapi dengan fasilitas pengendali mutu sadap.

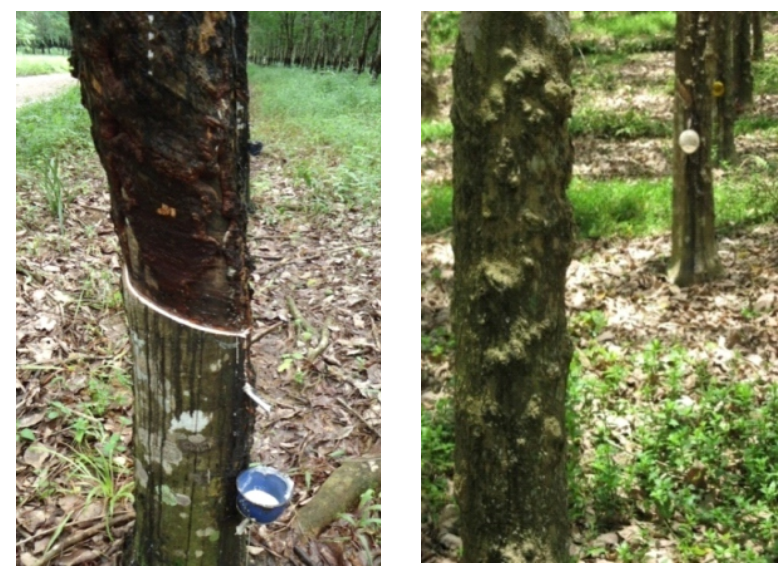

Gambar 1. Panel sadap bermutu buruk dan benjolan-benjolan pada kulit pulihan disebabkan luka kayu

\section{Teknologi Pisau Sadap}

Kegiatan menyadap di perkebunan karet di Indonesia sampai dengan saat ini umumnya masih menggunakan pisau sadap konvensional (Gambar 2). Pisau sadap konvensional dapat menghasilkan kualitas yang baik apabila digunakan oleh tenaga penyadap yang sudah terampil. Pisau sadap konvensional dioperasikan secara manual, yaitu dengan cara ditarik oleh tenaga penyadap. Pisau sadap ini berbentuk lempengan logam yang bagian ujung terdapat bengkokan $50^{\circ}-60^{\circ}$ dan bagian pangkal dipasang kayu untuk pegangan penyadap. Panjang pisau sadap pada umumnya 20 - 25 $\mathrm{cm}$. Pisau sadap setelah digunakan akan tumpul sehingga diperlukan pengasahan setiap hari karena ketajaman pisau akan berpengaruh terhadap konsumsi kulit yang secara normal baku tebal kulit yang diiris sekali menyadap tidak lebih dari $1,5 \mathrm{~mm}$. 


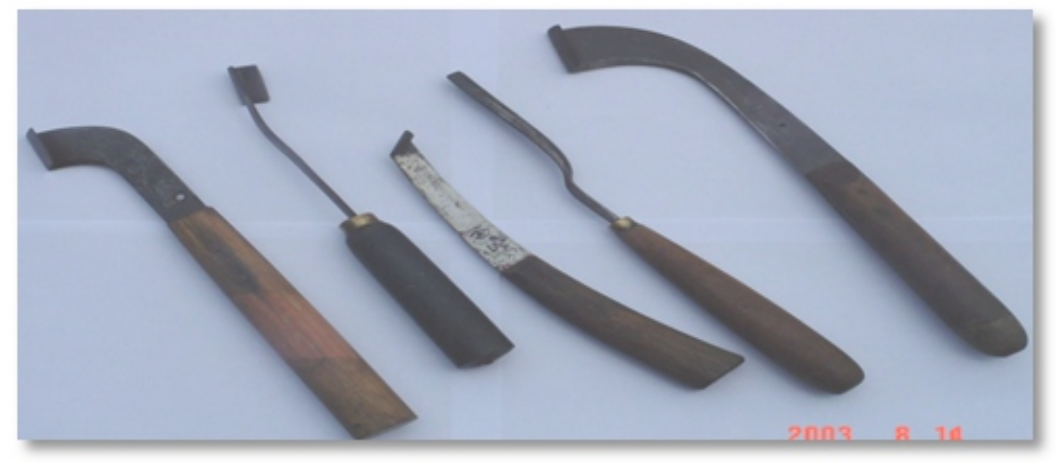

Gambar 2. Aneka bentuk pisau sadap konvensional

Kualitas hasil penyadapan yang kurang prima akibat penggunaan pisau sadap konvensional oleh tenaga penyadap yang tidak terampil sangat terkait dengan proses penyadapan pada saat mengiris pohon, konsentrasi menyadap terpecah dalam dua hal, yaitu :

- Secara fisik: melakukan gerakan menekan dan menarik pisau.

- Secara psikis (pikiran) : harus dapat menjaga kualitas sadap.

Kedua konsentrasi tersebut mempercepat tingkat kelelahan penyadap. Konsekuensi dari kelelahan penyadap menyebabkan berkurangnya konsentrasi penyadap, sehingga irisan kulit tidak terjaga kualitasnya serta berkurangnya jumlah pohon yang mampu disadap. Agar penyadap tidak cepat letih, diperlukan pisau sadap yang tajam dengan gagang yang sesuai karakteristik genggaman tangan setiap penyadap. Pisau yang tajam dapat menghasilkan sayatan setipis mungkin untuk membuka sumbatan lateks sisa penyadapan hari sebelumnya di bibir pembuluh lateks. Sayatan kulit yang tipis akan dapat menghemat pemakaian kulit dalam jangka panjang sampai berakhirnya umur ekonomis pengelolaan tanaman karet sekitar 25 - 30 tahun. Gagang pisau sadap yang sesuai dengan karakteristik genggaman penyadap membantu penyadap lebih rileks, lebih kokoh memegang dan menarik pisau ketika menyayat kulit. Gagang pisau konvensional yang lurus dan polos menyebabkan penyadap harus menggenggam gagang tersebut dengan lebih erat agar pisau tidak mudah terlepas saat menyayat kulit. Energi genggaman tersebut dapat dikurangi pada saat menekan dan menarik pisau dengan cara mngubah bentuk gagang menjadi lebih bersifat ergonomis, sehingga setiap jemari penyadap duduk secara tepat dan lebih kuat di dalam lekukan yang ada pada gagang pisau sesuai dengan karakter genggaman dan kebiasaan masing-masing penyadap.

Dalam penelitian Velasquez et al. (2016) dan Meksawi et al. (2012) dilaporkan bahwa penggunaan alat terkait dengan proses produksi karet dapat menimbulkan risiko kelainan tulang mulai dari penyadapan, pengumpulan hasil, hingga ke produksi karet sit. Untuk itu diperlukan alat yang sesuai dengan postur genggaman (ergonomis) yang dapat mendorong keselamatan dan kenyamanan bekerja khususnya pada penyadapan. Mata pisau yang tajam dan gagang yang ergonomis dapat mengurangi tingkat kelelahan penyadap ketika bekerja sehingga dapat menyadap pohon lebih banyak, tetapi belum sepenuhnya mengendalikan mutu sadap dengan baik. Oleh karena itu, pisau sadap harus dilengkapi dengan perangkat yang dapat mengendalikan mutu sadap ketika menyayat kulit. Kombinasi dari ketiga elemen tersebut (mata pisau, pengendali mutu, dan gagang ergonomis) yang dibingkai dalam desain pisau sadap ergonomis (Gambar 3) diyakini mampu meningkatkan prestasi dan kualitas penyadapan dalam satu siklus ideal pengelolaan tanaman karet. 


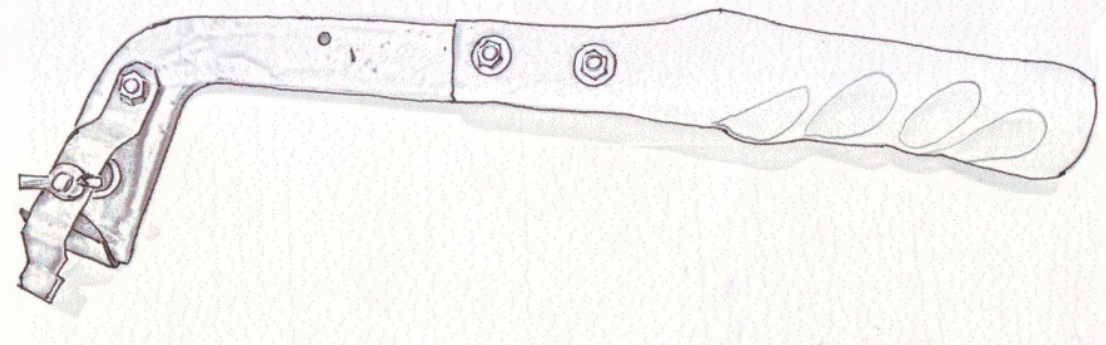

Gambar 3. Prototipe pisau sadap Bi-cut

Penggunaan pisau sadap ergonomis dalam mengeksploitasi tanaman karet selain mengurangi ketergantungan terhadap tenaga penyadap terampi. Harga pisau ini juga lebih murah dibandingkan pisau sadap konvensional sehingga dapat mengurangi biaya produksi agribisnis karet. Pada pisau sadap konvensional, pengausan mata pisau akibat pengasahan yang berulang menyebabkan seluruh komponen pisau harus diganti dengan pisau baru, sedangkan pisau sadap ergonomis yang diganti hanyalah mata pisau saja dengan harga lebih murah. Gagang dan tangkai pisau tetap dapat dipergunakan secara berulang.

\section{Inovasi Pisau Sadap Bi-Cut}

Hasil penelitian Wibowo (2017) dapat disimpulkan tiga sisi lemah pisau sadap konvensioal, yaitu : a) boros penggunaan bahan baja karena ketika mata pisau aus, seluruh komponen pisau sadap tidak dapat dipakai lagi, b) jika dipergunakan penyadap tidak terampil maka mutu sadap menjadi jelek, dan c) pisau konvensional cepat menimbulkan keletihan, sehingga konsumsi kulit kurang terkontrol. Berbagai bentuk dan dimensi pisau sadap sudah pernah dikembangkan oleh beberapa peneliti sebelumnya, seperti pisau sadap mekanis (Sail \& Muhamad, 1994; Wibowo, 2011), pisau sadap semi mekanis (Wicaksono, 2015), desain pisau sadap manual dari representasi beberapa daerah (Wibowo, 2017; Wibowo \& Sumarmadji, 2006) dan rancangan pisau sadap berdasarkan quality functional deployment dan model kano (Ginting et al., 2015; Persson, 1987), akan tetapi cenderung tetap mengacu kepada bentuk tradisionil merek Fauna yang diproduksi oleh German.

Sebuah inovasi untuk mengatasi kelemahan pisau sadap konvensional telah dilakukan oleh Pusat Penelitian Karet pada tahun 2016. Prototipe pisau sadap ergonomis untuk menyadap tanaman karet merupakan teknologi baru di bidang peralatan penyadapan. Pisau sadap ergonomis (Gambar 3) didesain terdiri atas empat komponen, yaitu 1) mata pisau yang dapat dibongkar-pasang dan dapat diatur maju-mundur atau depanbelakang, 2) lengan pengendali kedalaman sadapan yang dapat diatur maju-mundur, 3) tangkai pisau yang terbuat dari baja dan memiliki tonjolan pengendali konsumsi kulit serta cekungan seperempat elips untuk jalur keluarnya kulit hasil sayatan, 4) gagang pisau ergonomis yang sesuai karakteristik genggaman penyadap.

Mata pisau menggunakan logam berkualitas, sehingga ketajamannya lebih dari pisau biasa (Mabie et al., 1987; Nash, 1977). Jika mata pisau sudah mengalami pengausan, maka penggantian hanya dilakukan terhadap matanya saja, sedangkan tangkai pisau dan gagang pisau tetap dapat dipergunakan untuk waktu yang lebih lama. Pergantian mata pisau dapat dilakukan setiap 3-4 bulan sekali.

Pada sekitar mata pisau dirancang bentuk dan tambahan komponen yang dapat mengendalikan mutu sadap, terutama untuk mengendalikan kedalaman sadap dan konsumsi kulit. Jarak antara lekukan mata pisau dengan tonjolan di ujung tangkai pisau adalah ukuran konsumsi kulit sekali menyadap, sedangkan jarak antara dinding 
belakang pisau dengan plat pada lengan penegendali merupakan ukuran kedalaman sadapan.

Keseluruhan komponen besi pisau sadap tersebut dipasangkan pada gagang pisau yang sesuai dengan tipe genggaman penyadap (Gambar 4), yaitu:

- Tipe Genggam: gagang pisau dipeluk penuh oleh kelima jari penyadap. Empat jari mencengkram dari sisi kanan, sedangkan ibu jari berada di sisi kiri pisau.
- Tipe Tekan: gagang pisau digenggam oleh keempat jari dari sisi kanan, sedangkan ibu jari menekan pisau dari posisi dari posisi atas gagang.

- Tipe Tunjuk : tiga jari penyadap memegang dari sisi kanan gagang, sedangkan ibu jari memegang dari sisi kiri gagang. Akan tetapi jari telunjuk menekan pisau dari posisi atas gagang.

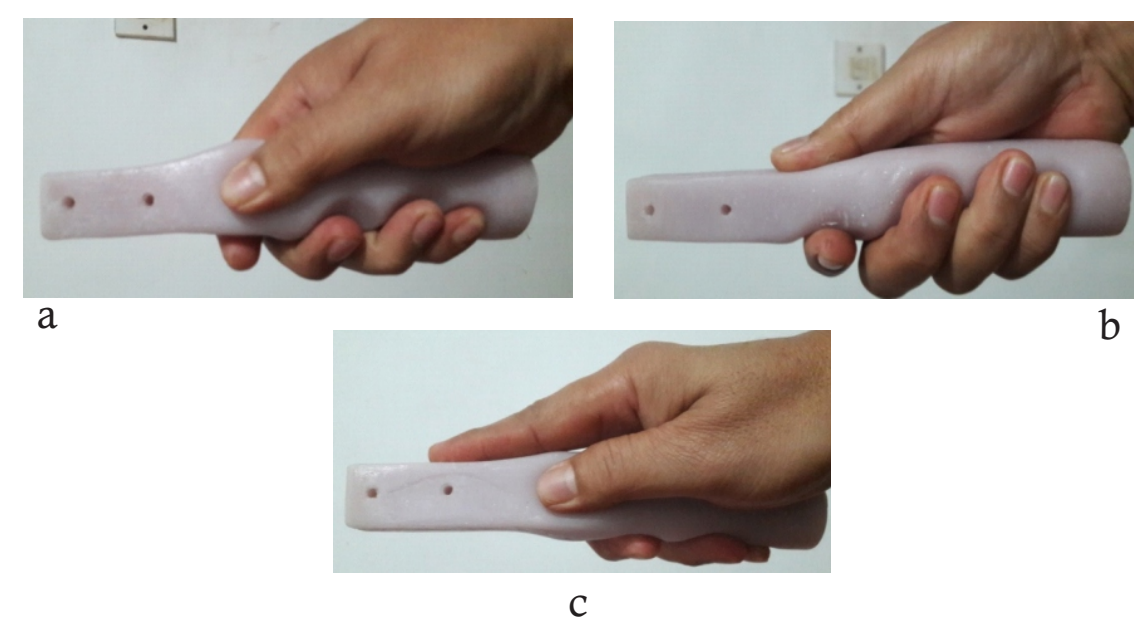

Gambar 4. Tipe gagang pisau Bi-cut (a) tipe genggam, (b) tipe tekan, dan (c) tipe tunjuk.

\section{Hasil Pengujian}

Pisau sadap ergonomis memiliki bobot berkisar 180-185 gr. Bobot pisau tersebut masih cukup ideal jika digunakan untuk menyadap tanaman karet. Hasil penelitian (Tabel 2) menunjukkan bahwa penggunaan pisau sadap konvensional pada saat menyadap tanaman karet oleh beberapa penyadap, yaitu membutuhkan waktu selama 15-17 detik/pohon. Artinya penggunaan pisau sadap ergonomis dibandingkan penggunaan pisau sadap konvensional memiliki kecepatan lebih lambat, dengan catatan penyadap harus membiasakan terlebih dahulu menggunakan pisau sadap ergonomis dengan lama adaptasi sekitar 2-3 minggu.

Tabel 2. Lama penyadapan tanaman karet oleh tiga orang penyadap

\begin{tabular}{|c|c|c|c|}
\hline \multirow{2}{*}{ Penyadap } & \multicolumn{2}{|c|}{ Pisau Sadap } & \multirow{2}{*}{ Selisih } \\
\hline & Bi-Cut & Konvensional & \\
\hline 1 & 21.98 & 17.60 & 4.37 \\
\hline 2 & 21.50 & 15.33 & 6.17 \\
\hline 3 & 20.38 & 16.86 & 3.53 \\
\hline $\begin{array}{l}\text { Rataan } \\
\text { S. deviasi }\end{array}$ & $\begin{array}{c}21.29 \\
0.82\end{array}$ & $\begin{array}{c}16.60 \\
1.16\end{array}$ & 4.69 \\
\hline
\end{tabular}




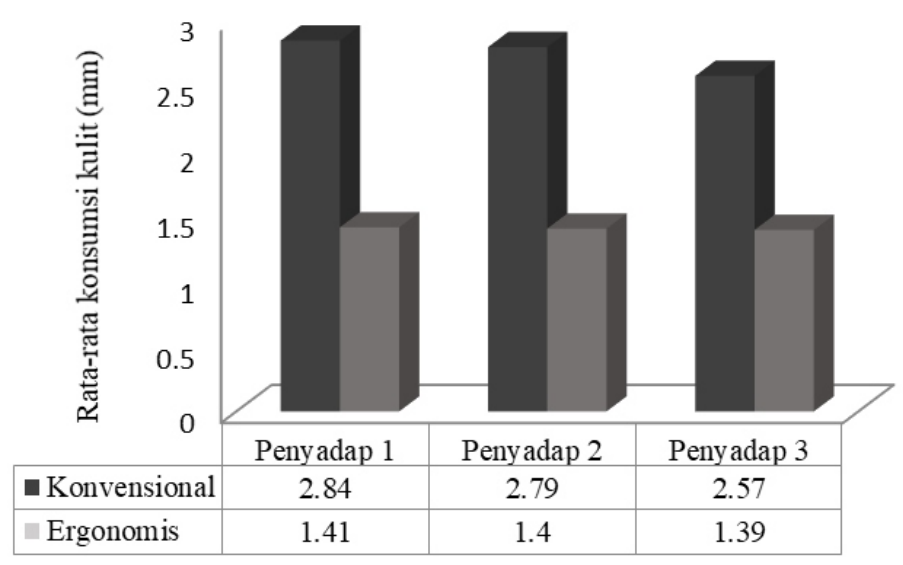

Gambar 5. Ketebalan kulit hasil sayatan menggunakan pisau Bi- Cut dan konvensional

Hasil penelitian menunjukkan bahwa secara statistik, jenis pisau sadap (Gambar 5) berbeda sangat nyata (uji Duncan pada $\alpha=$ $0,05)$ terhadap konsumsi kulit, namun tidak berbeda nyata terhadap produksi lateks (g/p/s) (Gambar 7) dan kedalaman sayatan. Hasil pengujian juga menunjukkan bahwa konsumsi kulit dengan penggunaan pisau sadap konvensional lebih tebal yaitu sebesar $2,73 \mathrm{~mm}$ dengan $\mathrm{CV}=16,1-26,7 \%$ dibandingkan dengan pisau sadap ergonomis yaitu sebesar 1,40 $\mathrm{mm}$ dengan $\mathrm{CV}=15$,7$17,2 \%$. Gambar 5 menunjukkan bahwa penggunaan pisau Bi-cut dapat menghasilkan tebal sayatan yang sesuai standar sekitar 1,5 $\mathrm{mm}$ dan lebih konsisten meskipun digunakan oleh penyadap kurang terampil. Dari segi bisnis, penggunaan pisau sadap ergonomis dapat meningkatkan umur ekonomi tanaman karet menjadi panjang (25-30 tahun).

Produksi lateks (g/p/s) pada masingmasing penyadap dengan menggunakan pisau sadap ergonomis dan pisau konvensional disajikan pada Gambar 6. Berdasarkan uji statistik (uji Duncan pada $\alpha=0,05$ ) menunjukkan bahwa produksi lateks tidak dipengaruhi oleh tipe genggaman dan jenis pisau, namun kecenderungan produksi lateks $(\mathrm{g} / \mathrm{p} / \mathrm{s})$ dengan pisau sadap ergonomis lebih rendah dibandingkan dengan pisau sadap konvensional, namun secara statistik tidak berbeda nyata. Hal tersebut diduga karena adanya perbedaan ketebalan kulit sayatan pada saat menyadap.

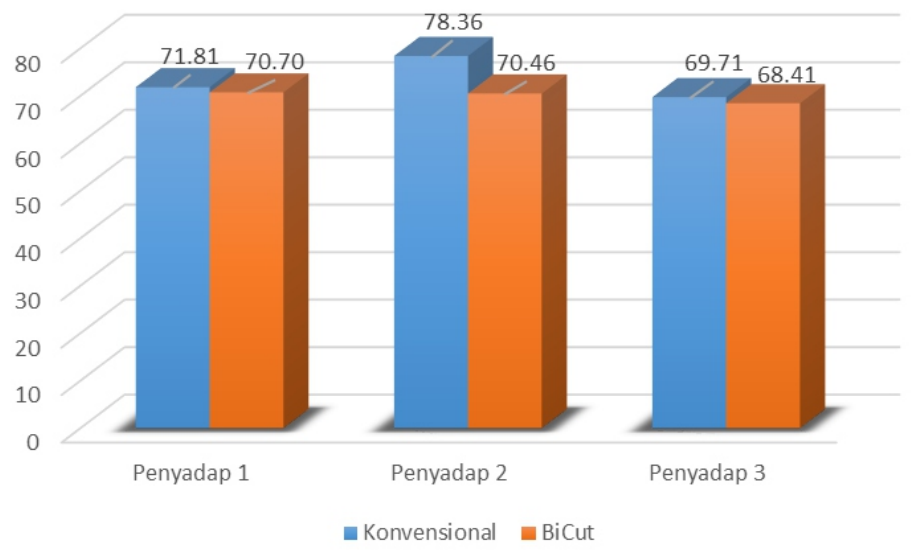

Gambar 6. Produksi lateks (g/p/s) dari tanaman yang disadap menggunakan pisau sadap konvensional dibandingkan dengan pisau Bi-cut. 
Kedalaman penyadapan memperlihatkan bahwa rata-rata penggunaan pisau sadap ergonomis $68,50 \%$ pohon disadap kurang 1,5 $\mathrm{mm}$ dibandingkan pisau sadap konvensional hanya $57,70 \%$. Hal ini mengindikasikan bahwa penyadap lebih berani menyayat kulit lebih dalam ke arah kambium tanpa melukai kayu, sehingga menghasilkan getah yang lebih tinggi sebab semakin banyak pembuluh lateks yang tersayat oleh pisau. Penyetelan pengatur kedalaman sadap diperlukan terutama pada pertanaman yang kurang seragam meskipun mengurangi kecepatan menyadap.

\section{Keunggulan Pisau Bi-cut}

Penggunaan pisau sadap ergonomis dalam mengeksploitasi tanaman karet selain mengurangi ketergantungan terhadap tenaga penyadap terampil karena dapat dipergunakan oleh penyadap yang kurang terampil, pisau ini juga berbiaya lebih murah sehingga dapat menekan biaya produksi agribisnis karet. Pada pisau sadap konvensional, pengausan mata pisau akibat pengasahan yang berulang menyebabkan seluruh komponen pisau harus diganti dengan pisau baru, sedangkan pisau sadap ergonomis yang diganti hanyalah mata pisau saja dengan harga lebih murah. Gagang dan tangkai pisau tetap dapat dipergunakan secara berulang.

Berdasarkan penelitian awal bahwa penggunaan pisau sadap ergonomis dapat mengiris kulit dengan asumsi rata-rata setebal 1,5 mm per kali sadap dengan tinggi sadapan $130 \mathrm{~cm}$ dan hari efektif penyadapan 112 hari, sehingga satu panel dapat disadap selama 7,74 tahun pada intensitas sadap d3 (disadap 3 hari sekali). Jika diakumulasikan satu siklus sadap dengan menggunakan panel kulit perawan (B0-1 dan B0-2) dan kulit pulihan (B1-1 dan B1-2) maka satu siklus sadap dapat mencapai 30,96 tahun, sedangkan penggunaan pisau sadap konvensional dengan kondisi keterampilan penyadap yang rendah hanya mampu menyadap sekitar 15,88 tahun per siklus produksi. Perhitungan tersebut dapat dijabarkan sebagai berikut :
Masa Penyadapan $=\frac{(130 \mathrm{~cm} / 0,15 \mathrm{~cm})}{112}=7,74$ tahun

sehingga dalam satu siklus didapat :

Masa Penyadapan (satu siklus) $=7,74 \mathrm{~cm} \mathrm{x} 4=30,96$ tahun

\section{Kesimpulan}

Mengingat demikian vitalnya fungsi penyadapan dalam agribisnis karet, maka peranan tenaga penyadap perlu menjadi prioritas untuk ditingkatkan. Sejalan dengan perkembangan teknologi klon unggul dan semakin sulitnya tenaga penyadap, maka pisau sadap ergonomis Bi-cut menjadi solusi untuk memecahkan masalah tenaga penyadap. Penggunaan pisau sadap ergonomis mampu mempertahankan umur ekonomis tanaman karet 25 - 30 tahun sebab penggunaan pisau sadap ergonomis Bi-cut mampu mengontrol konsumsi kulit $\leq 1,5 \mathrm{~mm}$ dan kedalaman sadapan sehingga tidak sampai melukai kayu/kambium. Umur tanaman yang panjang menyebabkan produksi karet dalam satu siklus menjadi lebih tinggi. Dengan adanya pisau sadap Bi-cut, maka kriteria tingkat keterampilan penyadap tidak lagi menjadi prioritas dan faktor pembatas untuk bekerja sebagai tenaga penyadap di perkebunan karet. Namun demikian, perlu dilakukan penelitian lebih lanjut berkaitan dengan jenis logam untuk mendukung penggunaan pisau sadap yang lebih efektif pada skala yang lebih luas dan tenaga kerja lebih banyak.

\section{Daftar Pustaka}

Andriyanto, M., \& Tistama, R. (2014). Perkembangan dan upaya pengendalian kering alur sadap pada tanaman karet (Hevea brasiliensis). Warta Perkaretan, 33(2), 89-102.

Ginting, R., Siregar, I., \& Ginting, T. U. H. S. (2015). Perancangan alat penyadap karet di Kabupaten Langkat Sumatera Utara dengan metode quality functional deployment (QFD) dan model kano. Jurnal Teknik Industri, 10(1), 33-40. 
Harieswantini, R., Subagja, H., \& Muksin. (2017). Analisis produktivitas dan pendapatan tenaga kerja penyadap karet di Kabupaten Jember. Journal of Social and Agricultural Economics, 10(1), 55-64.

Hendaryati, D. D., \& Arianto, Y. (2017). Statistik perkebunan Indonesia 2015-2017 (Karet). Jakarta, Indonesia: Direktorat Jendral Perkebunan.

Jacob, J., \& Krishnakumar, R. (2006). Tapping panel syndrome: what we know and what we do not know. In J. Jacob, R. R. Krishnakumar, \& N. M. Mathew (Eds.), Tapping panel dryness of rubber trees. Kottayam, India.: Rubber Research Institute of India.

Jacob, J. L., Prevot, J. C., \& Kekwick, R. G. O. (1989). General metabolism Hevea brasiliensis latex. In J. d'Auzac \& $\mathrm{H}$. Chrestin (Eds.), Physiology of rubber tree latex. Boca Raton, Florida: CRC Press.

Junaidi, U., \& Kuswanhadi. (1998, 8-9 Desember). Optimalisasi produktivitas klon melalui sistem eksploitasi. Tulisan disajikan pada Lokakarya Nasional Pemuliaan Karet 1998 dan Diskusi Nasional Prospek Karet Alam Abad 21, Medan.

Mabie, Hanilton, H., \& Reinholtz, C. F. (1987). Mechanisms and dynamics of machinery. Fourthedition. USA: Willey Publisher.

Meksawi, S., Tangtrakulwanich, B., \& Chongsuvivatwong, V. (2012). Musculoskeletal problem and ergonomic risk assessment in rubber tappers: a community-based study in Southern Thailand. International Journal and Industrial Ergonomics, 42(1), 129-135.

Nash, W. A. (1977). Theory and problems. Strength of materials, schaum outline series. USA: McGraw-Hill Inc.

Nugrahani, M. O., Rouf, A., Aji, Y. B. S., Widyasari, T., \& Rinojati, N. D. (2017). Kombinasi sistem sadap frekuensi rendah dan penggunaan stimulan untuk optimasi produksi dan penurunan biaya penyadapan di panel BO. Jurnal Penelitian Karet, 35(1), 59-79.
Pane, E., Siregar, T. H. S., \& Rahman, A. (2017). Model penanggulangan kelangkaan penyadap di perkebunan karet. Agrica, 10(1), 1-12.

Persson, S. (1987). Mechanics of Cutting Plant Material. An ASAE Monograph. St Joseph, Michigan: ASAE.

Sail, R. M., \& Muhamad, M. (1994). Factors associated with non-adoption of technology by rubber smallholders. Pertanika Journal Social Science \& Humaniora, 2(1), 29-41.

Senevirathna, A. M. W. K., Wilbert, S., Perera, S. A. P. S., \& Wijesinghe, A. K. H. S. (2007). Can tapping panel dryness of rubber (Hevea brasiliensis) be minimised at field level with better management. Journal of the Rubber Research Institute of Sri Lanka, 88, 7787. doi:10.4038/jrrisl.v88i0.1819.

Setiono, Aji, Y. B. S., Nugrahani, M. O., Rouf, A., \& Rimpun, A. (2016). Uji pendahuluan penyadap dengan "sirkel" cutting system menggunakan stimulan gas. Warta Perkaretan, 35(2), 121-134.

Siagian, N., \& Siregar, T. H. S. (2011). Pemeriksaan kualitas sadapan untuk mendukung produktivitas yang tinggi. Warta Perkaretan, 30(1), 26-33.

Siagian, N., \& Siregar, T. H. S. (2013). Evaluasi produktivitas tanaman karet dengan sistem tanam ganda pada skala komersil. Warta Perkaretan, 32(1), 16-24.

Siregar, T. H. S., Lukman, Junaidi, U., Kuswanhadi, \& Sutardi. (1997, 30-31 Juli). Sistem penyadapan yang efisien di perkebunan karet. Tulisan disajikan pada Seminar Apresiasi Teknologi Peningkatan Produktivitas Lahan Perkebunan, Medan.

Soumahin, E. F., Obouayeba, S., Dick, K. E., Dogbo, D. O., \& Anno, A. P. (2010). Low intensity tapping system applied to clone PR 107 of Hevea brasiliensis (Muell. Arg): Results of 21 years of exploitation in Southeastern Cote d'Ivoire. African Journal of Plant Science, 4(5), 145-153. 
Sumarmadji, Istianto, Munthe, H., \& Siagian, N. $\left(2003^{\mathrm{a}}\right)$. Laporan akhir, studi peningkatan efisiensi teknologi budidaya karet. Diakses dari Balai Penelitian Sungei Putih, Pusat Penelitian Karet.

Sumarmadji, Junaidi, \& Atminingsih. (2009). Perkembangan sistem eksploitasi dalam upaya pencapaian produktivitas optimal. Warta Perkaretan, 28(2), 61-72.

Sumarmadji, Siregar, T. H. S., \& Karyudi. (2003 , 10-11 Desember). Sistem eksploitasi yang lebih sesuai untuk menunjang produktivitas karet yang optimal. . Tulisan disajikan pada Konferensi Nasional Menunjang agribisnis Lateks dan Kayu, Medan.

Velasquez, S., Valderrama, S., \& Giraldo, D. (2016). Ergonomic assessment of natural rubber processing in plantations and small enterprises. Ingenieria y Competitividad, 18(2), 233-246.
Wibowo, S. A., \& Sumarmadji. (2006). Pisau sadap manual yang efektif mendukung sistem eksploitasi karet EXPEX-315. Jurnal Penelitian Karet, 24(2), 146-153.

Wibowo, S. A. (2011). Disain dan kinerja pisau sadap elektrik untuk tanaman karet. (Tesis), Institut Pertanian Bogor, Bogor.

Wibowo, S. A. (2017). Disain pisau sadap manual untuk mengoptimalkan produksi tanaman karet (Hevea brasiliensis). Jurnal Penelitian Karet, 35(2), 179-188.

Woelan, S., Junaidi, \& Pasaribu, S. A. (2012). Optimasi produksi klon IRR seri 200 dengan menggunakan beberapa sistem sadap di pengujian plot promosi. Jurnal Penelitian Karet, 30(2), 75-85. 